This item was submitted to Loughborough's Research Repository by the author.

Items in Figshare are protected by copyright, with all rights reserved, unless otherwise indicated.

\title{
Facilitators and barriers of care transitions - comparing the perspectives of hospital and community healthcare staff
}

PLEASE CITE THE PUBLISHED VERSION

https://doi.org/10.1016/j.apergo.2020.103339

PUBLISHER

Elsevier

VERSION

AM (Accepted Manuscript)

\section{PUBLISHER STATEMENT}

This paper was accepted for publication in the journal Applied Ergonomics and the definitive published version is available at https://doi.org/10.1016/j.apergo.2020.103339.

\section{LICENCE}

CC BY-NC-ND 4.0

\section{REPOSITORY RECORD}

Burford, Evi, Michael Fray, and Patrick Waterson. 2021. "Facilitators and Barriers of Care Transitions Comparing the Perspectives of Hospital and Community Healthcare Staff'. Loughborough University. https://hdl.handle.net/2134/14136044.v1. 


\title{
Facilitators and Barriers of Care Transitions - Comparing the Perspective of Hospital and Community Healthcare Staff
}

\author{
Eva-Maria Carman ${ }^{\mathrm{a}, \mathrm{b}^{*}}$, Michael Fray ${ }^{\mathrm{c}}$ and Patrick Waterson ${ }^{\mathrm{a}}$ \\ ${ }^{a}$ Human Factors and Complex Systems Group, \\ Loughborough Design School, \\ Loughborough University, \\ Loughborough, UK. \\ ${ }^{\mathrm{b}}$ Trent Simulation and Clinical Skills Centre, \\ Queens Medical Centre, \\ Nottingham University Hospitals NHS Trust, \\ Nottingham, UK. \\ ${ }^{\mathrm{c}}$ Environmental Ergonomics Research Centre, \\ Loughborough Design School, \\ Loughborough University, \\ Loughborough, UK.
}

*Corresponding author:

Eva-Maria Carman

Human Factors and Complex Systems Group, Loughborough Design School,

Loughborough University

Loughborough, LE11 3TU, United Kingdom.

Tel: 07475340954

Email: e.burford@1boro.ac.uk, eva.burford@nuh.nhs.uk 


\title{
Facilitators and Barriers of Care Transitions - Comparing the Perspective of Hospital and Community Healthcare Staff
}

\begin{abstract}
As a patient moves from hospital back home to receive community-based care, quality of care and patient safety are often put at risk. This study aimed to analyse the discharge process to identify and compare the barriers and facilitators within the context of the system in which they occur, from the perspective of both hospital and community healthcare staff. The results were derived from the analysis of 348 incident reports, the observation of five discharge planning meetings with hospital staff, three focus groups with hospital staff, and six focus groups with community healthcare staff. Five themes representative of the barriers and four themes representative of the facilitators for this process were identified from both hospital and community healthcare staff's perspective. These were then discussed in the context of the subsystem, hospital or community healthcare setting, in which they occur.
\end{abstract}

Keywords: Barriers; Facilitators; Systems Approach

Word count $=7050$

Highlights:

- Interorganisational interactions and linking of subsystems has a key effect on work in the discharge process.

- Considering facilitators and barriers using a systems approach, allows for the identification of their connections to other work system elements.

- Through comparison of these two subsystems and identification of the points of intersection for barriers and facilitators for these two subsystems, potential areas for improvement are revealed. 


\section{Introduction: patient safety and care transitions}

Healthcare needs to meet six care requirements, namely: to be safe, effective, efficient, patient-centred, timely and equitable (Institute of Medicine Committee on Quality of Health Care in America, 2001). To achieve these requirements, patients will need input and collaboration from various healthcare providers and specialties (Bodenheimer, 2008; Carayon and Friesdorf, 2006; Wears et al., 2012). This requires healthcare staff to communicate effectively (Braithwaite et al., 2013), provide care coordination and participate in care transitions (Patterson et al., 2004). Care transitions occur in numerous healthcare settings (Hoonakker et al., 2019), for example during shift change, transfer between units, and with discharge of the patient to their home (WHO Collaborating Centre for Patient Safety Solutions, 2007). For the care transition involved in the hospital discharge process, which is a particularly complex healthcare process (Wong et al., 2011), collaboration of different work systems (Werner et al., 2016) and coordination of these different subsystems is required to ensure continuity of care occurs (McDonald et al., 2007; O’Daniel and Rosenstein, 2008).

Healthcare staff often encounter challenges and barriers in coordinating care for a patient's discharge (Bodenheimer, 2008). Barriers to the discharge process identified in the literature included poor cross system communication and coordination, lack of availability of supporting services (Anthony and Hudson-Barr, 1998; Wong et al., 2011), a lack of involvement of the patient and their family (Anthony and Hudson-Barr, 1998), and delayed and poor information transfer (Nagpal et al., 2010). Additional barriers identified were associated with discharge planning, "unmatched needs", transport problems, timing issues (Wong et al., 2011) and a lack of patient readiness (Anthony and Hudson-Barr, 1998). As a result of these barriers, numerous problems may arise, including the breakdown of quality of care and increased risk to patient safety (Arbaje et al., 2014; Hilligoss and Vogus, 2015). Problems associated with a breakdown in this process include medication-related events due to information transfer problems (WHO Collaborating Centre for Patient Safety Solutions, 2007), delayed transfers of care which accrue substantial costs for healthcare organisations (Bate, 2015), readmissions, reduced quality of care and injury to patients (Forster et al., 2003).

Strategies or facilitators to the discharge process identified in the literature included accurate and complete information transfer, checking the accuracy of information 
(Bisantz et al., 2012), conducting the discharge process in a timely manner, good communication with the patient, their family and all healthcare staff involved (Anthony and Hudson-Barr, 1998) as well as adopting a multidisciplinary approach (Wong et al., 2011). Current studies aimed at investigating means to improve the discharge process are focused on care transitions for specific diseases (Werner et al., 2016) or are predominantly aimed at one subsystem in the discharge process (Werner et al., 2019), for example the effect of hospital-based discharge planning (Gonçalves-Bradley et al., 2016; Phillips et al., 2004; Wong et al., 2011).

As the knowledge of how to optimise discharge care transitions is still incomplete and minimal (Arbaje et al., 2014), the call to better understand the challenges and coping strategies healthcare staff employ in care transitions that cross organisations (Hilligoss and Vogus, 2015) to inform the redesign process (Carayon et al., 2019), would be a recommended approach to investigating the discharge process. As demonstrated above many studies only target one subsystem in this process, and as a result there appears to be a gap in the literature with regards to compiling the different perspectives of the subsystems involved in the discharge process, how these subsystems are connected and the implications of this for barriers and facilitators.

\subsection{Study aims and objectives}

This study focused on the discharge process for patients from Health Care of the Older Person (HCOP) wards in one hospital to their home or a care home, where they require follow up care provided by community nurses and therapists. The aim of the study was to identify and understand the connections, barriers and facilitators for the different subsystems involved in the discharge care transition process. A key aspect of this aim was to understand how the perspective of these two subsystems on the same process differed and how these two subsystems were connected. To address this aim, the study adopted three objectives, namely:

1. Through a systems analysis, depict the work system configurations from hospital and community healthcare staffs' perspectives. The purpose of this was to highlight the connections between these two subsystems for this healthcare process.

2. Identify the barriers and facilitators for each of these subsystems. 
3. Identify how these barriers and facilitators may be linked to each other as well as to other system elements.

\section{Study design and methods}

\subsection{Study Design}

As the discharge process requires input from different healthcare subsystems (McDonald et al., 2007; O'Daniel and Rosenstein, 2008), different points in the process and the perspective of different healthcare staff involved in the discharge process were considered. The phases of analysis and the respective data sources are depicted in Figure 1.

\section{Figure 1 here}

The qualitative methods adopted in this study included focus groups, observations and analysis of reported incidents. Focus groups were held with both hospital staff from the HCOP wards from one hospital in an Acute NHS Trust (Trust A) and community healthcare staff from a Community NHS Foundation Trust (Trust C). The pre-discharge analysis also consisted of observation sessions of the weekly Target Action Group (TAG) meetings that were on the discharge plans of patients from the HCOP wards from the hospital (Trust A). The post-discharge analysis also included an analysis of incident reports related to problems associated with the discharge process filed by community healthcare staff (Trust C).

Qualitative methods were selected as the method choice, as this approach is highly suited to study people, their experience and phenomena in the context they occur and collect naturally occurring data (Bowling, 2002; Mays and Pope, 1995). The healthcare field is increasingly acknowledging the value of this type of research (Sim, 1998). Furthermore, incident reports as a data source is "one of the most widely implemented improvement strategies" (Macrae and Stewart, 2019, p. 2) in healthcare, and analysing adverse incidents has been seen as a key mechanism to improving patient safety (Macrae and Stewart, 2019; Magrabi et al., 2010). As a result, this type of data source was included in this study. 


\subsection{Setting and Context}

The study took place in two large UK NHS Trusts, which are organisations within the NHS that consist of numerous services and sites that are grouped together either serving a geographical area or specialised function. The Acute NHS Trust (Trust A) involved in this study provides acute and specialist services to 2.5 million people in a city and surrounding communities, as well as specialist services for a further 3 - 4 million people from across the region. The Community NHS Foundation Trust (Trust C) involved in this study, provides a variety of healthcare services across 140 locations and has 1,872,000 patient contacts annually, including community-based care (Care Quality Commission, 2019). The directorates involved in this study included three location teams across the county, which deliver services to approximately 373,000 patients, $44.83 \%$ of the registered population of the county (Public Health England, 2019).

\subsection{Sample and Participants}

For the pre-discharge analysis, a total of 28 participants took part in the observation phase and focus groups. For the observation phase, five weekly TAG meetings were observed, and 14 hospital staff members provided participant information. The participants included discharge coordinators, ward managers, and nursing staff. The mean number of years involved in patient care of the staff that attended the meetings was 17 years ( \pm 12 years). Three focus groups were conducted with hospital staff from the HCOP wards at Trust A and the sample size of the focus groups consisted of three, five and six participants. The participants included discharge coordinators, deputy ward managers, occupational therapists, physiotherapists, nursing staff and a hospital consultant. The mean total number of years involved in patient care was 12 years $( \pm 9$ years).

For the post-discharge analysis, a total of 39 participants took part in the focus groups and 348 reported incidents were analysed. For the six focus groups conducted with community healthcare staff (Trust C), seven participants took part in each of the five of the focus groups and the sixth focus group had four participants. The mean total number of years involved in patient care of the participants of the community focus groups was 17 years ( \pm 11 years). The participants included community and district nurses, locality managers, community physiotherapists, occupational therapists, assistant practitioners, and a team leader of a care home. The 348 reported incidents were all associated with 
the discharge process for adult patients requiring healthcare input from community healthcare staff either in their own home or care homes. The reported incidents were from the three directorates from Trust $\mathrm{C}$ that were involved in the focus groups.

\subsection{Procedure}

All data capturing was conducted in 2016 . The focus groups with community healthcare staff were conducted between May and July 2016, and the focus groups with hospital staff were conducted between October and November 2016. The observation of the TAG meetings with hospital staff were conducted between August and September 2016. All reported incidents associated with the discharge process for adult patients requiring healthcare input from community healthcare staff between April 2014 to March 2016 for the three directorates from Trust C were extracted in September 2016 from the organisation's incident reporting database.

\subsection{Data Collection Methods}

\subsubsection{Observation Session of TAG Meetings}

Between five and seven wards took part in these weekly meetings, and over the five meetings observed, the discharge plans for 777 patients were discussed (mean $=155$ patients discussed per meeting, $\mathrm{SD}= \pm 27$ ). As the data was collected through unobtrusive observation, the analysis was limited to the verbal content of the meeting.

\subsubsection{Analysis of Incident Reports}

A total of 348 incidents formed the sample, and these reports reflected problems community staff encountered while providing care to recently discharged adult patients. These reports were filed by community-based healthcare staff (e.g. nursing staff and rehabilitation staff). The aim of the qualitative analysis was to identify key themes relating to barriers that occurred in the incidents reported. The fields from the incident reports analysed was limited to the fields for free narrative text, namely details of the incident, additional details and an outcome description.

\subsubsection{Focus Groups}

Exploratory focus groups were held with hospital and community healthcare staff involved in the discharge process and were comprised of two consecutive components. Each component was approximately 60 minutes in duration. The first component 
focused on the things that go wrong and possible error recovery strategies. The second component focused on aspects that work well and was derived from questions by Hollnagel (2014, p. 153). The main discussion was guided by the first author (EC) through a series of open questions, included in Appendix A. Participants were encouraged to freely discuss any topics that arose as a result of these questions.

Prior to the start of the focus group, the project was described, and informed consent was obtained from all participants. The discussions from the focus group were recorded using audio recorders and a summary of the key points raised was compiled on a flipchart. The audio data was subsequently transcribed and analysed together with the compiled summary, initially by the first author (EC) and subsequently reviewed by the paper's co-authors (PW, MF).

\subsection{Data Analysis}

Thematic analysis, which is a method for identifying and organising emerging themes relating to the description of phenomenon (Braun and Clarke, 2012, 2006), was used for the qualitative analysis of all the data. The analysis was guided by the SEIPS 2.0 model (Holden et al., 2013) to determine common themes from a systems perspective. This model was selected as it is healthcare-specific, incorporates a systems approach, and is applicable to a large number of healthcare scenarios (Carayon et al., 2014, 2006). Furthermore, this version of the model assists in generating an understanding of the collaborative work required and that various work system configurations may produce barriers and facilitators (Carayon et al., 2020). Initial data reduction was done by using pre-set codes created from the sociotechnical work system and outcome components described in the SEIPS 2.0 model. Following this an inductive approach was adopted to compile themes related to barriers and facilitators for each subsystem. The results were analysed using NVivo 11 Software (QSR International Pty Ltd, 2015). Each data source was analysed independently before the results were compared and combined during the interpretation stage.

Similarly, for the work system configurations, each data source was analysed independently before the results were compiled to form individual configurations for the hospital and community healthcare setting. The format and method for generating the work system configuration was taken from the example provided in Figure 2 of the 
original paper by Holden and colleagues (2013, p. 1675). The aims of this analysis were to provide a description of these two perspectives and capture how these two subsystems, which function spatially and temporally removed, may be linked for this one type of healthcare process. Since this analysis was performed, other studies (e.g. Hay, Klonek, \& Parker, 2020; Werner et al., 2020) have also adopted a similar approach to generating work system configurations.

\subsection{Ethical Considerations}

Ethical and organisational approval was granted by the Loughborough University Ethics Approval (Human Participants) Sub-Committee, Trust A and Trust C. All information was stored confidentially, and the anonymity of the participants was ensured as none of the individual results were made available.

\section{Findings}

3.1 Work system configurations from the perspective of hospital and community healthcare staff

This study focused on care transitions of patients from HCOP wards (Trust A) to their home or a care home where they required additional care and treatment from community healthcare staff (Trust $\mathrm{C}$ ). The configural diagrams and the work system components from both perspectives are depicted in Figure 2.

\section{Figure 2 here}

From the perspective of hospital staff, the people involved in their subsystem included other healthcare staff at their site (e.g. therapists and pharmacists), the patient and their family. The tasks included discharge planning, completing the necessary pre-discharge tasks (e.g. ordering equipment, completing assessments, booking transport, submitting referrals, and ordering medication) and initiating the discharge. Key tools and technology needed to complete the tasks included access to physical documents (e.g. patient file), and up-to-date and accurate online information. Although both work system configurations rely on similar types of information that are stored online, staff mentioned that often they did not have access to online systems in the other work system (dashed line $c$, Figure 2). For the discharge process to occur in the hospital, internal subsystems need to coordinate and communicate (e.g. pharmacy, transport), 
specific roles (i.e. discharge coordinator) and procedures (e.g. discharge planning) have been created to support this process, as well as communication and collaboration between organisations needs to occur. Furthermore, organisational pressures such as bed availability will influence this process for both work system configurations.

From the community healthcare staff's perspective, although there were some similarities, there were some key differences in the work system configurations. The people that differed were community healthcare staff (e.g. GPs, therapists and community nurses). Although one would expect the presence of both staff groups, hospital and community, in both work system configurations, a common barrier mentioned by both groups was a lack of cross system interaction of staff. The patient and their family are two of the constants across these two work system configurations (solid line $a$, Figure 2). The tasks included receiving referrals, triaging them as well as planning and conducting an initial and follow-up visits. The task associated with conducting an initial visit is dependent on the hospital task of initiating the discharge (dashed line $b$, Figure 2). The key organisation of work elements identified by community staff included communication and collaboration between organisations, creating staff capacity to cope with incoming referrals, process-specific roles (i.e. triage nurse) and procedures that have been created to promote the safety of this process (e.g. cut-off times). The main internal environment factor for the discharge process is that of the patient's home. Even though this factor is physically present in the community healthcare work system configuration, this needs to be considered for several of the tasks in the hospital work system configuration, namely for the tasks of discharge planning and completing the pre-discharge tasks (dashed line $d$,Figure 2).

The external environment factor that influences the discharge process and both work system configurations was the day of the week the discharge occurred. An example of the effect of this is highlighted in excerpt below:

"it's about wider organisational issue on both sides, so we talk about a seven-day service ... But it's not a true seven-day service... there is availability of the service over the weekend ... the other services don't do that in tandem so we can't access all the services we need ... subsequently we will have reduced capacity in week." (Community focus group 2) 
The end outcomes, which are the states resulting once aspects have gone wrong, that were identified in all the data sources (focus groups, observations and incident reports) included the patient being readmitted to hospital, the discharge being delayed or the patient not receiving the necessary follow-up care or medication. In the next section barriers that may contribute to these outcomes were identified and discussed.

\subsection{Barriers for the discharge process}

The results from the previous section have already highlighted several of barriers that originate as a result of these two subsystems functioning spatially and temporally apart. In addition to the focus groups, the observation sessions and analysis of the incident reports were used to identify themes relating to barriers to the discharge process. The observation sessions assisted in identifying barriers to the discharge process from hospital staffs' perspective and the barriers that usually affect the process before the patient has left the hospital. The results from the incident reports identified barriers that were experienced by community healthcare staff but may have originated in the hospital work system.

Five main themes were extracted that represented the barriers to the discharge process from the perspective of both hospital and community healthcare staff. The main themes consisted of barriers associated with hospital discharge-related tasks; a lack of cross system interaction, communication and capacity; patient's health and capacity; organisation-related barriers and the family's expectations and lack of support for the process. The key differentiation between the hospital and community healthcare themes was in some of the subthemes identified. The main themes and subthemes of barriers identified from the hospital and community healthcare data and how they connect are summarised in Figure 3. The relevant work system components, as depicted in Figure 2 , are listed for each main theme and are illustrated in the text below with quotes from participants in the focus groups.

Figure 3 here

Themes associated with hospital discharge related tasks included the pre-requisite tasks for the discharge process not being completed on time or accurately. These barriers originate as a result of events in the hospital work system and included poor, missing 
or insufficient assessments, documentation and information; problems associated with discharge planning, delayed transport; the time of day the discharge occurs (e.g. late in the day); the home environment is not prepared; insufficient or incorrect equipment, medical supplies (e.g. dressings) and medications have been provided and medical devices have been left in situ (e.g. cannulas).

Themes associated with cross system interaction, communication and capacity limitations included communication and information transfer problems, limited capacity of external service providers, a lack of understanding of the subsystems, a lack of ownership of the patient, cut off times of services missed, and not having access to the patient. Communication and information transfer were related to the task of sending referrals (work system component Ta2, Figure 2) as this is a form of formal cross system communication and these barriers result in the necessary information not being transmitted. The problems with referrals, which were mentioned in all six focus groups held with community staff (Trust C), included no referral being sent, being sent late, being inaccurate or inappropriate and the template for the referral being inappropriate. This last point refers to the prompts for hospital staff on the referral form being insufficient for the information required by community healthcare staff. The subtheme of a lack of understanding of the subsystems involved a lack of understanding of procedures and services offered, as well as a lack of trust between systems. An example of a lack of awareness of the services offered in the community is highlighted in the following excerpt:

"I think that goes back to ... what the hospital knows of our role, as I don't think they've got a clear definition of what we do sometimes and what we don't do ..."

(Community focus group 4)

Themes associated with the patient's health and capacity related barriers included the intrinsic factors of the patient such as their expectations, knowledge, medical condition, behaviour and ability. Regarding the patient's medical condition, this may result in time pressure for the discharge to occur such is the case for End of Life patients. This also included the funding status of the patient as this may affect the types of services a patient can access. 
The theme of organisation-related barriers included the effect of organisational pressures, adopting a risk adverse culture, certain policies and procedures, and a lack of capacity of services. Organisational pressures were associated with meeting targets and having enough beds available in the hospital. An example of one of the comments by participants relating to the effect of meeting targets and how the problem may be linked to inappropriate admissions was:

"You get them upstairs constantly shouting ... for beds. People being schlepped out inappropriately because people have been admitted inappropriately"

(Hospital focus group 3).

The above comment also related to the subtheme of adopting a risk adverse culture whereby healthcare staff err on the side of caution, particularly with patients that are admitted to HCOP wards. Policies and procedures that provide barriers to the discharge process include an incompatibility of the services offered during different days of the week across the system (as highlighted by the quote in section $3.1 \mathrm{pp} .9$ ), delays as a result of the discharge pathway the patient is on, and a lack of consideration of supporting services' cut off times for accepting new patients.

The family related aspects included family having unrealistic demands and expectations concerning the care and support the patient requires or is entitled to as well as not cooperating with the staff regarding the discharge. An example of this would be the family changing their minds on the day of the discharge regarding the plans.

\subsection{Facilitators for the discharge process}

The themes relating to facilitators of the discharge process were derived from the focus groups held with hospital and community healthcare staff and are summarised in Table 1. Four main themes were extracted that represented the facilitators both hospital and community healthcare staff use, with the key differentiation identified for the subthemes. The four main themes consisted of good information availability, accuracy and collection methods; good cross system coordination, communication and interaction; successful and timely completion of pre-discharge tasks and good organisation of work at a subsystem level. 
Key information sources that were considered as facilitators from both perspectives included online systems, key documents and utilising the family and patient as an information source. For community staff, the transmission of specific information was a key facilitator. This included information on the patient, their home environment, key contact information, current medication and risks and safety concerns staff need to know.

The theme of good cross system coordination, communication and interaction referred to good communication and interaction across all the involved system elements including the patient, their family, and between the different services and subsystems. The importance of coordination and teamwork across subsystems required for preventing a readmission is described in the excerpt below:

"... sending them back into hospital is always going to be the last resort. It would be a case of what can we get into place, what equipment can we get, who [staff] can we get involved to try keep them at home."

(Community focus group 3 )

The theme of successful and timely completion of pre-discharge tasks refers to tasks that need to be done prior to the patient being discharged from hospital. These include ensuring the patient is ready for discharge, accurate assessments, having access and having considered the patient's home in discharge planning, ordering equipment, dispensing medication, booking follow-up appointments and sending the necessary referrals.

The theme of good organisation of work at a subsystem level refers to how the subsystem level organises their work to meet the needs of the system and ensure a successful outcome for this process. This includes individual behaviours, scheduling the discharge before noon, good teamwork and sharing information, specific organisational aspects such as policies, procedures and roles as well as understanding how to work within this complex process. Specific job roles that are facilitators included discharge coordinators in the hospital setting and the triage role in the community setting. An additional subtheme identified only by community healthcare staff included creating capacity through triaging referrals, work scheduling and being aware and using alternative resources to provide unplanned care. The alternative 
resources included same-day delivery of equipment and external services that can provide quick short-term care. An example of how the community service has organised their work to support anticipation and the flexibility required for the discharge process is described below:

"We usually have our second responder, but we also have got somebody that triages ... you can ring them, and ... it's [ordering equipment] not something extra you got to do when you get back. So, I think as a service we have changed quite a lot how we run to allow for the crises" (Community Focus group 2).

This example describes several system levels, namely the person, task and organisation, that have adapted to promote safety and learn how to cope with the pressures within the system.

\subsection{Compilations of the results}

Based on the results presented above, several conclusions can be drawn regarding the connection between barriers, facilitators and the two different subsystems included in this study. Examples of the barriers and facilitators that are connected for the discharge process across the hospital and community healthcare setting have been presented in Table 2. Several of the main themes for the barriers and facilitators identified can be considered "two sides of the same coin". These include the barrier of hospital discharge related tasks not completed and the facilitator of successful and timely completion of pre-discharge tasks, and the barrier of cross system interaction, communication and capacity and the facilitator of good cross system coordination, communication and interaction. The absence of the facilitator would suggest the presence of the barrier.

\section{Table 2 here}

Some facilitators have arisen as a consequence of barriers within the subsystem or the other subsystem. An example of this was the barrier of missing and inaccurate information for which community staff have developed the facilitator of independently gathering information. This may also have developed due to the barrier of a lack of trust between systems. For the barriers of missing equipment and insufficient support, although these were identified in the community healthcare subsystem, they originate as a result of tasks in the hospital subsystem. Community healthcare staff have developed the facilitator of using alternative resources to provide unplanned care and 
for same day delivery of equipment. The final example in the table is that of a barrier for the hospital subsystem that is a facilitator for the community healthcare subsystem. Whereas care home cut-off times are seen as a barrier for hospital staff as it may result in the patient being readmitted if not adhered to, it is a facilitator in the community healthcare subsystem as it links to work scheduling and ensures patient safety.

\section{Discussion}

\subsection{Summary of Findings}

Healthcare systems have evolved into systems of systems and to improve safety and quality of care, a systems approach is needed (Carayon et al., 2018; Hofoss and Deilkås, 2008). To understand the work and actions of the discharge process, the work configurations for the two subsystems involved in this process were depicted in Figure 2. This figure highlights how two subsystems in one healthcare process may be removed and function partially separately but are still dependent on each other to deliver care requirements. This spatial and temporal distribution of work in healthcare systems is receiving increased acknowledgement to the point that the SEIPS 2.0 model has recently been revised to reflect this in greater detail (Carayon et al., 2020). The SEIPS 3.0 model (Carayon et al., 2020) recognises how the patient and their family are the constant in numerous healthcare subsystems, as is also depicted by line a in Figure 2 in this study. However, the SEIPS 2.0 model (Holden et al., 2013) was the more suitable model for this study, as this version focuses more on the work system components, their connections and collaborative work processes and how these may produce barriers and facilitators (Carayon et al., 2020). Furthermore, capturing these interorganisational system interactions and linking of different system elements is essential for understanding safety in these complex systems (Waterson et al., 2015).

As the patient and their family are usually the only common physical link between subsystems (Carayon et al., 2020), they play an important role in care processes (Bisantz et al., 2012). An indication of the effect of the role the patient and their family can play in the barriers and facilitators staff experience for this process is visible in numerous subthemes presented Figure 3 and Table 1. The facilitator of good family communication and involvement is linked to the barrier of families' expectations and lack of support which were both identified for the hospital and community healthcare subsystems. The patient and their family as a potential resource has been highlighted 
by the WHO (2007), as patients may have knowledge on their condition that healthcare staff may need to know (Howard-Anderson et al., 2016) and play an essential role in the work associated with post-discharge care as highlighted by Werner et al. (2019). The literature also suggests interventions should aim to enhance the patientprofessional collaboration elements of this process (Xiao et al., 2019) and empower patients with regards to selfcare (Leppin et al., 2014).

The degree of separation of these two subsystems was also the cause for several other barriers identified in this study. One such barrier, present across numerous other healthcare processes and extensively cited in the literature, is that of communication problems and missing information (Andrews et al., 1997; Forster et al., 2003; Werner et al., 2017; Wong et al., 2011). This barrier has been associated with poor quality of care and high costs (Naylor, 2000). An additional barrier that is associated with information transfer problems is that of problems with referrals. This is both a prerequisite task, an information transferring task and a professional process element, and was one of the most mentioned themes in the results from community focus groups and incident reports. This is also reflected as a key problem with care coordination in the literature (Bodenheimer, 2008).

The identified barriers suggest that these not only cause delays to the process, as revealed by the observation data, but also cause numerous incidents that community healthcare staff witness, as reported by the results from the incident report data. The incident report data suggest that certain incidents occur due to particular pre-discharge tasks not being completed prior to discharging the patient. One of the subthemes identified by both hospital and community healthcare staff included the patient not being ready for discharge. Literature has found this to be a known barrier (HowardAnderson et al., 2016), predominantly as a result of hospital pressures such as bed availability (Wong et al., 2011).

Some barriers, even though they originate in one system, have effects that present in the other system. An example of this is the barrier of the home environment not prepared to receive the patient, most likely created in the hospital setting by not considering the home environment. The limited understanding of the home environment by healthcare staff in the hospital setting for this patient group is a known 
barrier (Holden et al., 2015). As a result of the care transition, the "work environment" transfers from a healthcare setting to the home environment. This has numerous implications for other work elements including a transfer of responsibility (Xiao et al., 2019), as well as affecting task aspects, equipment requirements and medication safety. Additional examples include problems associated with referrals, as well as insufficient or incorrect equipment, medical supplies, and medications sent with the patient. These barriers, which present in the community healthcare subsystem, originate in the hospital subsystem when problems are encountered with completing the pre-discharge tasks (Figure 2, Work system component Ta2). However, community staff have developed facilitators to mitigate some of the effects of these barriers, for example using alternative resources to provide same day delivery of equipment and care. Consequently, this is associated with an additional cost to the organisation.

Four main themes associated with facilitators were identified. Several of these are related to supplemental interpersonal approaches, which allow for the work around of operational barriers and failures (Hilligoss and Vogus, 2015). Examples of these include cross-system collaboration, information collection methods, as well as successful and timely completion of pre-discharge tasks. The cross-system collaboration has been identified as a necessity to enhancing care transitions (Werner et al., 2019). The focus groups also highlighted that adopting a multidisciplinary team approach was a facilitator and literature suggests that this approach can improve safety (Blegen et al., 2010) and facilitate communication (Anthony and Hudson-Barr, 1998).

The above examples in addition to the barriers and facilitators described in the results highlight how the discharge process is a dynamic process that involves a "bilateral interdependence" (Bisantz et al., 2012) among hospital and community healthcare staff. The barriers identified highlighted some of the ways quality of care can break down between care transitions and put the patient at risk (Arbaje et al., 2014; Hilligoss and Vogus, 2015).

\subsection{Practical Implications and Future Work}

In addition to the quality of care and safety aspect, the discharge process has also been identified as a potential area for cost containment (Gonçalves-Bradley et al., 2016). By ensuring the process is as quick and safe as possible, inpatient costs can be reduced and 
by ensuring adequate post-discharge support, unplanned readmissions can be reduced (Phillips et al., 2004). Although the findings from this current study predominanlty highlight the patient safety and work process aspects, which are also tied to cost implications, the specific costs identified included those associated with mitigating error, for example the costs of ordering same-day equipment. Furthermore by ensuring a quick, efficient and safe discharge the discomfort and pain associated with adverse incidents to the patient and their family can be avoided.

The use of a systems approach in this study, guided by previous work (Carayon et al., 2014, 2006; Holden et al., 2013), provided the opportunity to consider the effects of behaviour, equipment, teams and related system elements on patient-related tasks and how these may enhance the quality of care (National Quality Board, 2013). This study identified not only key system areas that are confirmed by the literature as contributing to negative outcomes for the discharge process, but also identified connections between barriers, facilitators and the context and wider system in which they occur. In order to intervene in care transitions and redesign the process to enhance safety and productivity, one needs to describe the subsystems, how they connect and how they work together to provide the requirements for this process (Kianfar et al., 2019). An example of considering the wider system to support interventions for the discharge process would be to design referrals used in the hospital setting by considering the information requirements of the end receiver of the referrals, in this context the community healthcare staff. The information required could be identified through the some of the facilitators community healthcare staff use to support their work. This alternative approach would result in the necessary information being "pulled" instead of the presumed required information being "pushed" through the system.

Furthermore, to improve the functioning of this process, one needs to consider not only the process as a whole but also the barriers of the individual subsystems and how these may be connected. This is as the barriers in these subsystems may differ and changes in the one subsystem may create barriers in the other subsystem. The results from this study revealed that staff had developed facilitators to counteract some of the barriers experienced. The facilitators included communication, individual strategies, and organization of work at a subsystem level. These results highlight the need to have a thorough understanding of the interpersonal and organisational dynamics that shape this 
process (Hilligoss and Vogus, 2015), and the barriers staff face and the facilitators they use (Carayon et al., 2019). The results from this study provided these elements through depiction of the work system configurations, the barriers and facilitators for this process and how they may be linked across the two subsystems involved in this one healthcare process. By highlighting the connections between the two subsystems and how barriers and facilitators may be associated with each other, insight is provided on how the system functions despite these barriers and how alterations in one subsystem may have effects in the other subsystem. By understanding the resources staff are currently using to mitigate the barriers within the system to keep the process functioning, it is essential to consider these when redesigning the process so that safety and work capacity is not reduced as a result of potentially removing these resources. Facilitators may also provide an indication of a potential means of enhancing work in this system and therefore could form the basis of an intervention by using these facilitators to create more "formal" procedures.

This study provides a basis for the design of an intervention to enhance safety and quality of the discharge process. Future work in this field would be to use this knowledge to inform changes to the tasks, procedures and tools utilised in the discharge process that will assist in bridging the divide and in ensuring the continuity of care between hospital and community healthcare services. It would be recommended when attempting to enhance this process, the key barriers of the different subsystems involved, and the facilitators staff use be considered.

\subsection{Study Limitations}

The limitations of this study included those associated with field-based research, objectivity of qualitative research and self-reported data, the use of reported incidents as a data source and the sample included. Although with field-based research there is a lack of control of extraneous variables and the effect of the presence of the researcher, especially in observations, as healthcare processes need to be understood in the environment that they occur in, this was unavoidable. The limitation associated with qualitative research included the objectivity of the data, however these methods provide in-depth information on behaviour in context (Cronbach, 1975; Jick, 1979). Several additional limitations associated with analysing incident reports include bias, the effect of the structure of the form used to capture the incident details, they may not be 
representative of the events occurring in the system and cannot be considered as a "true" record of adverse events (Andrews et al., 1997; Boxwala et al., 2004). However, these provide a form of insight into incidents that may otherwise not be captured (Boxwala et al., 2004). Several of the above limitations were addressed in that data was collected from numerous independent sources and through triangulation, the rigor and validity of the results was enhanced (Jick, 1979). The limitation with regards to the sample included that not all stakeholders in this process were included and the sample size of the hospital focus groups were limited. The sample in this study was predominantly limited to nursing and therapy staff, and did not include other key stakeholders, for example patients, their families, other healthcare staff such as pharmacists and general practitioners. The hospital focus group size, which consisted of 14 participants, was limited as the hospital had a smaller population size of staff that met the inclusion criteria.

\section{Conclusions}

This study builds on available literature (e.g. Werner et al., 2019) by expanding the scope of the systems approach and actively seeking connections between barriers, facilitators and work system elements. In addition, this study is unique to others that have explored barriers and facilitators for the discharge process for this patient population group (e.g. Arbaje et al., 2014) as this study considered the discharge process from a system's perspective and explored how two subsystems involved in the discharge process are connected. This places the barriers and facilitators in the context within which they occur, and, by adopting and depicting both a hospital and community staff perspective individually, the unique barriers and facilitators that are present in their individual work systems can be identified. Moreover, these results revealed that often staff will develop facilitators to counteract barriers, which thereby provide greater insight into barriers and the work system. As barriers may be created in a subsystem different from the one, they present in, the work system as whole needs to be considered when trying to improve the process.

This study explored the views of different healthcare staff involved in the discharge process regarding barriers and facilitators. A total of five themes were extracted that represented barriers and four themes that represented facilitators for the discharge 
process for patients from HCOP wards to their home or care home still requiring treatment and support from community healthcare staff. An essential aspect of this study was to consider the perspective of hospital and community healthcare staff and how this may differ for the same healthcare process. To provide the context and framework for connecting the barriers experienced by staff and the facilitators for this process, a systems analysis depicting these two work system configurations was conducted. The results, specifically how barriers and facilitators and how the two subsystems intersect, reveal potential areas of improvement, and provide insight and key information necessary for design of quality and safety interventions for the discharge process.

\section{Acknowledgements}

The funding for this project was provided by East Midlands Academic Health Science Network Patient Safety Collaborative (EMAHSN) and Health Education East Midlands as a result of a successful joint bid for funding by Health Partnerships, a Division within Trust C and Loughborough University Design School. The authors are grateful to all the colleagues at the Health Partnerships, Loughborough University Design School and Trust $\mathrm{A}$ and Trust $\mathrm{C}$ for their help and support. Many thanks to Paul Smeeton, Bill Brown (Health Partnerships), and Cheryl Crocker (Patient Safety Collaborative) for their support they gave to the project, as well as the hospital and community staff that participated in this study.

\section{References}

Andrews, L.B., Stocking, C., Krizek, T., Gottlieb, L., Krizek, C., Vargish, T., Siegler, M., 1997. An alternative strategy for studying adverse events in medical care. Lancet (London, England) 349, 309-13. doi:10.1016/S0140-6736(96)08268-2

Anthony, M.K., Hudson-Barr, D., 1998. Successful Patient Discharge. J. Nurs. Adm. 28, 48-55. doi:10.1097/00005110-199803000-00010

Arbaje, A.I., Kansagara, D.L., Salanitro, A.H., Englander, H.L., Kripalani, S., Jencks, S.F., Lindquist, L.A., 2014. Regardless of Age: Incorporating Principles from Geriatric Medicine to Improve Care Transitions for Patients with Complex Needs. J. Gen. Intern. Med. 29, 932-939. doi:10.1007/s11606-013-2729-1

Bate, A., 2015. Delayed transfers of care in the NHS.

Bisantz, A.M., Carayon, P., Miller, A., Khunlertkit, A., Arbaje, A.I., Xiao, Y., 2012. 
Using Human Factors And Systems Engineering To Improve Care Coordination. Proc. Hum. Factors Ergon. Soc. Annu. Meet. 56, 855-859. doi:10.1177/1071181312561179

Blegen, M.A., Sehgal, N.L., Alldredge, B.K., Gearhart, S., Auerbach, A.A., Wachter, R.M., 2010. Improving safety culture on adult medical units through multidisciplinary teamwork and communication interventions: the TOPS Project. Qual. Saf. Heal. Care 19, 346-350. doi:10.1136/qshc.2008.031252

Bodenheimer, T., 2008. Coordinating Care - A Perilous Journey through the Health Care System. N. Engl. J. Med. 358, 1064-1071. doi:10.1056/NEJMhpr0706165

Bowling, A., 2002. Research Methods in Health: Investigating Health and Health Services, Second Edi. ed. Open University Press, Buckingham.

Boxwala, A.A., Dierks, M., Keenan, M., Jackson, S., Hanscom, R., Bates, D., Sato, L., 2004. Organization and Representation of Patient Safety Data: Current Status and Issues around Generalizability and Scalability. Jamia 11, 468-478. doi:10.1197/jamia.M1317.Errors

Braithwaite, J., Clay-Williams, R., Nugus, P., Plumb, J., 2013. Health Care as a Complex Adaptive System, in: Hollnagel, E., Braithwaite, J., Wears, R.L. (Eds.), Resilient Health Care. Ashgate Publishing Ltd., pp. 57-73.

Braun, V., Clarke, V., 2006. Using thematic analysis in psychology. Qual. Res. Psychol. 3, 77-101. doi:10.1191/1478088706qp063oa

Braun, V., Clarke, V., 2012. Thematic analysis, in: APA Handbook of Research Methods in Psychology, Vol. 2: Research Designs: Quantitative, Qualitative, Neuropsychological, and Biological. American Psychological Association, Washington, D.C., pp. 57-71.

Carayon, P., Friesdorf, W., 2006. Human Factors and Ergonomics in Medicine, in: Salvendy, G. (Ed.), Handbook of Human Factors and Ergonomics. John Wiley \& Sons, Inc., Hoboken, NJ, USA, pp. 1517-1537. doi:10.1002/0470048204.ch58

Carayon, P., Schoofs Hundt, A., Hoonakker, P., 2019. Technology barriers and strategies in coordinating care for chronically ill patients. Appl. Ergon. 78, 240247. doi:10.1016/J.APERGO.2019.03.009

Carayon, P., Schoofs Hundt, A., Karsh, B.-T., Gurses, A.P., Alvarado, C.J., Smith, M., Flatley Brennan, P., 2006. Work system design for patient safety: the SEIPS model. Qual. Saf. Health Care 15 Suppl 1, i50-8. doi:10.1136/qshc.2005.015842 Carayon, P., Wetterneck, T.B., Rivera-Rodriguez, A.J., Schoofs Hundt, A., 
Hoonakker, P., Holden, R.J., Gurses, A.P., 2014. Human factors systems approach to healthcare quality and patient safety. Appl. Ergon. 45, 14-25. doi:10.1016/j.apergo.2013.04.023

Carayon, P., Wooldridge, A.R., Hoonakker, P., Schoofs Hundt, A., Kelly, M.M., 2020. SEIPS 3.0: Human-centered design of the patient journey for patient safety. Appl. Ergon. 84, 103033. doi:10.1016/J.APERGO.2019.103033

Carayon, P., Wooldridge, A.R., Hose, B.-Z., Salwei, M., Benneyan, J., 2018. Challenges And Opportunities For Improving Patient Safety Through Human Factors And Systems Engineering. Health Aff. 37, 1862-1869. doi:10.1377/hlthaff.2018.0723

Care Quality Commission, 2019. Nottinghamshire Healthcare NHS Foundation Trust. Cronbach, L.J., 1975. Beyond the two disciplines of scientific psychology. Am. Psychol. 30, 116-127. doi:10.1037/h0076829

Forster, A., Murff, H.J., Peterson, J.F., Gandhi, T.K., Bates, D., 2003. The incidence and severity of adverse events affecting patients after discharge from the hospital. Ann. Intern. Med. 138, 161-167. doi:10.7326/0003-4819-138-3200302040-00007

Gonçalves-Bradley, D.C., Lannin, N.A., Clemson, L.M., Cameron, I.D., Shepperd, S., 2016. Discharge planning from hospital. Cochrane Database Syst. Rev. 1. doi:10.1002/14651858.CD000313.pub5

Hay, G.J., Klonek, F.E., Parker, S.K., 2020. Diagnosing rare diseases: A sociotechnical approach to the design of complex work systems. Appl. Ergon. 86, 103095. doi:10.1016/j.apergo.2020.103095

Hilligoss, B., Vogus, T.J., 2015. Navigating Care Transitions: A Process Model of How Doctors Overcome Organizational Barriers and Create Awareness. Med. Care Res. Rev. 72, 25-48. doi:10.1177/1077558714563170

Hofoss, D., Deilkås, E., 2008. Roadmap for patient safety research: approaches and roadforks. Scand. J. Public Health 36, 812-817. doi:10.1177/1403494808096168

Holden, R.J., Carayon, P., Gurses, A.P., Hoonakker, P., Schoofs Hundt, A., Ozok, A., Rivera-Rodriguez, A.J., 2013. SEIPS 2.0: a human factors framework for studying and improving the work of healthcare professionals and patients. Ergonomics 56, 1669-1686. doi:10.1080/00140139.2013.838643

Holden, R.J., Schubert, C.C., Eiland, E.C., Storrow, A.B., Miller, K.F., Collins, S.P., 2015. Self-care barriers reported by emergency department patients with acute 
heart failure: A sociotechnical systems-based approach, in: Annals of Emergency Medicine. Mosby Inc., pp. 1-12.e2. doi:10.1016/j.annemergmed.2014.12.031

Hollnagel, E., 2014. Safety-I and Safety-II: The Past and Future of Safety Management. Ashgate Publishing Ltd., Farnham.

Hoonakker, P., Wooldridge, A.R., Hose, B.-Z., Carayon, P., Eithun, B., Brazelton, T.B., Kohler, J.E., Ross, J.C., Rusy, D.A., Dean, S.M., Kelly, M.M., Gurses, A.P., 2019. Information flow during pediatric trauma care transitions: things falling through the cracks. Intern. Emerg. Med. 1-9. doi:10.1007/s11739-01902110-7

Howard-Anderson, J., Busuttil, A., Lonowski, S., Vangala, S., Afsar-Manesh, N., 2016. From discharge to readmission: Understanding the process from the patient perspective. J. Hosp. Med. 11, 407-412. doi:10.1002/jhm.2560

Institute of Medicine Committee on Quality of Health Care in America, ., 2001.

Crossing the Quality Chasm: A New Health System for the 21st Century. Washington.

Jick, T.D., 1979. Mixing Qualitative and Quantitative Methods: Triangulation in Action. Adm. Sci. Q. 24, 602-611. doi:10.2307/2392366

Kianfar, S., Carayon, P., Schoofs Hundt, A., Hoonakker, P., 2019. Care coordination for chronically ill patients: Identifying coordination activities and interdependencies. Appl. Ergon. 80, 9-16. doi:10.1016/J.APERGO.2019.05.002

Leppin, A.L., Gionfriddo, M.R., Kessler, M., Brito, J.P., Mair, F.S., Gallacher, K., Wang, Z., Erwin, P.J., Sylvester, T., Boehmer, K., Ting, H.H., Murad, M.H., Shippee, N.D., Montori, V.M., 2014. Preventing 30-Day Hospital Readmissions. JAMA Intern. Med. 174, 1095. doi:10.1001/jamainternmed.2014.1608

Macrae, C., Stewart, K., 2019. Can we import improvements from industry to healthcare? BMJ 364, 11039. doi:10.1136/bmj.11039

Magrabi, F., Ong, M.-S., Runciman, W., Coiera, E., 2010. An analysis of computerrelated patient safety incidents to inform the development of a classification. J. Am. Med. Informatics Assoc. 17, 663-670. doi:10.1136/jamia.2009.002444

Mays, N., Pope, C., 1995. Rigour and qualitative research. BMJ 311, 109-12.

McDonald, K.M., Sundaram, V., Bravata, D.M., Lewis, R., Lin, N., Kraft, S.A., McKinnon, M., Paguntalan, H., Owens, D.K., 2007. Closing the Quality Gap: A Critical Analysis of Quality Improvement Strategies (Vol. 7: Care Coordination), Closing the Quality Gap: A Critical Analysis of Quality Improvement Strategies 
(Vol. 7: Care Coordination). Agency for Healthcare Research and Quality (US). Nagpal, K., Vats, A., Lamb, B., Ashrafian, H., Sevdalis, N., Vincent, C., Moorthy, K., 2010. Information Transfer and Communication in Surgery. Ann. Surg. 252, 225-239. doi:10.1097/SLA.0b013e3181e495c2

National Quality Board, 2013. Human Factors in Healthcare: a Concordat.

Naylor, M.D., 2000. A Decade of Transitional Care Research with Vulnerable Elders. J. Cardiovasc. Nurs. 14, 1-14. doi:10.1097/00005082-200004000-00004

O’Daniel, M., Rosenstein, A.H., 2008. Professional Communication and Team Collaboration, Patient Safety and Quality: An Evidence-Based Handbook for Nurses. Agency for Healthcare Research and Quality (US).

Patterson, E.S., Roth, E., Woods, D.D., Chow, R., Gomes, J.O., 2004. Handoff strategies in settings with high consequences for failure: Lessons for health care operations. Int. J. Qual. Heal. Care 16, 125-132. doi:10.1093/intqhe/mzh026

Phillips, C.O., Wright, S.M., Kern, D.E., Singa, R.M., Shepperd, S., Rubin, H.R., 2004. Comprehensive discharge planning with postdischarge support for older patients with congestive heart failure: a meta-analysis. JAMA 291, 1358-67. doi:10.1001/jama.291.11.1358

Public Health England, 2019. Local Authority Health Profiles [WWW Document]. URL https://fingertips.phe.org.uk/profile/health-profiles (accessed 12.10.17).

QSR International Pty Ltd, 2015. NVivo Qualitative Data Analysis Software.

Sim, J., 1998. Collecting and analysing qualitative data: issues raised by the focus group. J. Adv. Nurs. 28, 345-52.

Waterson, P., Robertson, M.M., Cooke, N.J., Militello, L.G., Roth, E., Stanton, N.A., 2015. Defining the methodological challenges and opportunities for an effective science of sociotechnical systems and safety. Ergonomics 1-35. doi:10.1080/00140139.2015.1015622

Wears, R.L., Perry, S.J., Patterson, E.S., 2012. Handoffs and Transitions of Care, in: Carayon, P. (Ed.), Handbook of Human Factors and Ergonomics in Health Care and Patient Safety. CRC Press, Taylor and Francis, Boca Raton, USA, p. 848.

Werner, N.E., Gurses, A.P., Leff, B., Arbaje, A.I., 2016. Improving Care Transitions Across Healthcare Settings Through a Human Factors Approach. J. Healthc. Qual. 38, 328-343. doi:10.1097/JHQ.0000000000000025

Werner, N.E., Malkana, S., Gurses, A.P., Leff, B., Arbaje, A.I., 2017. Toward a process-level view of distributed healthcare tasks: Medication management as a 
case study. Appl. Ergon. 65, 255-268. doi:10.1016/J.APERGO.2017.06.020

Werner, N.E., Rutkowski, R., Graske, A., Finta, M.K., Sellers, C.R., Seshadri, S., Shah, M.N., 2020. Exploring SEIPS 2.0 as a model for analyzing care transitions across work systems. Appl. Ergon. 88, 103141.

doi:10.1016/j.apergo.2020.103141

Werner, N.E., Tong, M., Borkenhagen, A., Holden, R.J., 2019. Performance-Shaping Factors Affecting Older Adults' Hospital-to-Home Transition Success: A Systems Approach. Gerontologist 59, 303. doi:10.1093/GERONT/GNX199

WHO Collaborating Centre for Patient Safety Solutions, 2007. Patient Safety Solutions Preamble-May 2007. Geneva.

Wong, E.L., Yam, C.H., Cheung, A.W., Leung, M.C., Chan, F.W., Wong, F.Y., Yeoh, E.-K., 2011. Barriers to effective discharge planning: a qualitative study investigating the perspectives of frontline healthcare professionals. BMC Health Serv. Res. 11, 242. doi:10.1186/1472-6963-11-242

Xiao, Y., Abebe, E., Gurses, A.P., 2019. Engineering a foundation for partnership to improve medication safety during care transitions. J. Patient Saf. Risk Manag. 24, 30-36. doi:10.1177/2516043518821497 


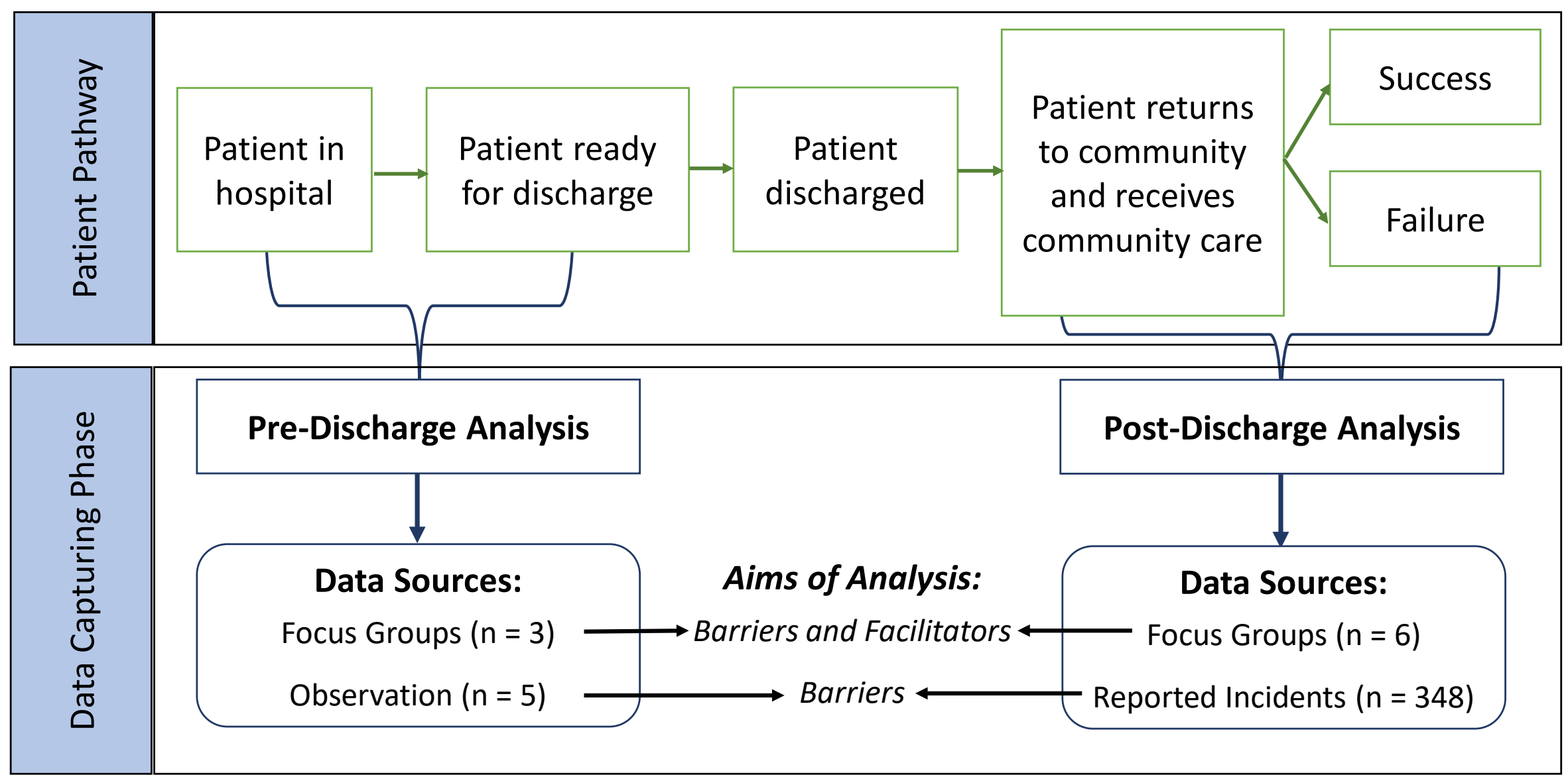

Figure 1: Description of the patient pathway for care transitions relating to the discharge process and the different analysis phases and data sources utilized. 


\begin{tabular}{|c|c|}
\hline $\begin{array}{c}\text { The Discharge Process from Hospital Staff's } \\
\text { Perspective }\end{array}$ & $\begin{array}{c}\text { The Discharge Process from Community Staff's } \\
\text { Perspective }\end{array}$ \\
\hline $\begin{array}{c}\text { External (EE1) } \\
\text { Environment }\end{array}$ & $\begin{array}{l}\text { External } \\
\text { Environment }\end{array}$ \\
\hline $\begin{array}{c}\text { Active Agent(s): Hospital healthcare staff (e.g. doctors, } \\
\text { nurses, therapists), patient, their family }\end{array}$ & $\begin{array}{c}\text { Active Agent(s): Community healthcare staff (e.g. } \\
\text { nurses, therapists), patient, their family }\end{array}$ \\
\hline \multicolumn{2}{|c|}{ Performance is shaped strongly by a combination of the following factors: } \\
\hline $\begin{array}{l}\text { Person(s) Factors: } \\
\text { - P1-Hospital Healthcare Staff: Knowledge of the patient's } \\
\text { current condition and home environment. Communication and } \\
\text { collaboration with other healthcare staff. } \\
\text { - P2-Patient: Patient is medically fit for discharge. The } \\
\text { complexity of their case has been considered as this will } \\
\text { influence the discharge plan. Patient is involved in the } \\
\text { process. } \\
\text { - P3-Patient's Family: The patient's family are involved in the } \\
\text { process and the decision making. }\end{array}$ & $\begin{array}{l}\text { Person(s) Factors: } \\
\text { - P2-Patient: Patient is medically fit for discharge. They are } \\
\text { involved in the process; have given consent and have received } \\
\text { the necessary education. } \\
\text { - P3-Patient's Family: The patient's family are involved in the } \\
\text { process, decision making and used as an information source. } \\
\text { - P4-Community Healthcare Staff: Communication and } \\
\text { collaboration with the patient, their family and other } \\
\text { healthcare staff involved. Knowledge of the patient's current } \\
\text { condition, previous medical history and needs. }\end{array}$ \\
\hline $\begin{array}{l}\text { Task Factors: } \\
\text { - Ta1: Discharge planning, which is influenced by the } \\
\text { complexity of the patient. } \\
\text { - Ta2: Completing pre-discharge tasks (e.g. prepare patient, } \\
\text { order equipment, complete assessments, book transport, } \\
\text { submit referrals, complete necessary documentation, order } \\
\text { medication). } \\
\text { - Ta3: Time the discharge occurs. }\end{array}$ & $\begin{array}{l}\text { Task Factors: } \\
\text { - Ta4: Receiving the necessary referrals, information and } \\
\text { documentation. The information available will affect this task. } \\
\text { - Ta5: Triage of the referrals and patients on caseload. This will } \\
\text { be affected by the number of urgent referrals. The information } \\
\text { available will affect this task. } \\
\text { - Ta6: Plan and conduct initial visit ( } b \text { - this is influenced by } \\
\text { the Ta3: time of the discharge.) Update care plan. }\end{array}$ \\
\hline $\begin{array}{l}\text { Technology (and Artefacts) Factors: } \\
\text { - T1: Availability and accuracy of online patient records } \\
\text { - T2: Access to written documents. Affected by legibility. }\end{array}$ & $\begin{array}{l}\text { Technology (and Artefacts) Factors: } \\
\text { - T1: Availability and accuracy of online patient records. }\end{array}$ \\
\hline $\begin{array}{l}\text { Organisation of Work Factors: } \\
\text { - O1: Subsystem coordination and communication (e.g. } \\
\text { Pharmacy, Transport and Discharge lounge) including } \\
\text { teamwork, sharing knowledge and information } \\
\text { - O2: Specific job roles (e.g. discharge coordinator) } \\
\text { - O3: Between organisation communication and collaboration } \\
\text { - O4: Effect of organisational pressure -Understanding the need } \\
\text { to "get patients out" } \\
\text { - O5: Procedures (e.g. Plan discharge upon admission) }\end{array}$ & $\begin{array}{l}\text { Organisation of Work Factors: } \\
\text { - O3: Between organisation communication and collaboration } \\
\text { - O4: Effect of organisational pressure } \\
\text { - O6: Triaging of referrals and work schedule structure to } \\
\text { create capacity and flexible. } \\
\text { - O7: Teamwork, sharing knowledge and information } \\
\text { - O8: Specific job roles (e.g. triage nurse) } \\
\text { - O9: Procedures (e.g. cut-off times for other services and } \\
\text { standard operating procedures for different areas) }\end{array}$ \\
\hline & $\begin{array}{l}\text { Internal Environment Factor: } \\
-\quad \text { IE1: Community staff have access to the patient and their } \\
\text { home, and the home environment has been prepared. }\end{array}$ \\
\hline \multicolumn{2}{|l|}{ External Environment Factor: EE1: Day of the week, Funding } \\
\hline \multicolumn{2}{|c|}{$\begin{array}{l}\text { a-The patient and their family are two constants across these two subsystems. } \\
b \text { - The task of plan and conducting initial visit by community staff (Ta6) is directly influenced by the task Ta3: time of the } \\
\text { discharge. } \\
\text { c-Both subsystems require information from online systems, but staff may not necessarily have access to the online systems, or } \\
\text { the different online systems may not link. } \\
d \text { - The patient's home (Internal environment factor IE1) should be considered for the tasks od discharge planning (Tal) and } \\
\text { completing the pre-discharge tasks (Ta2), which will influence the initial visit (Ta6). } \\
\text { This work system configuration of the discharge process is a high-level depiction of this complex process aimed at highlighting } \\
\text { the current connections of the two subsystems involved in the discharge process, and as a result is not an exhaustive list of all the } \\
\text { influencing factors. }\end{array}$} \\
\hline
\end{tabular}

Figure 2: The configural work system from the perspective of hospital and community healthcare staff involved in the discharge process of patients from HCOP wards. 


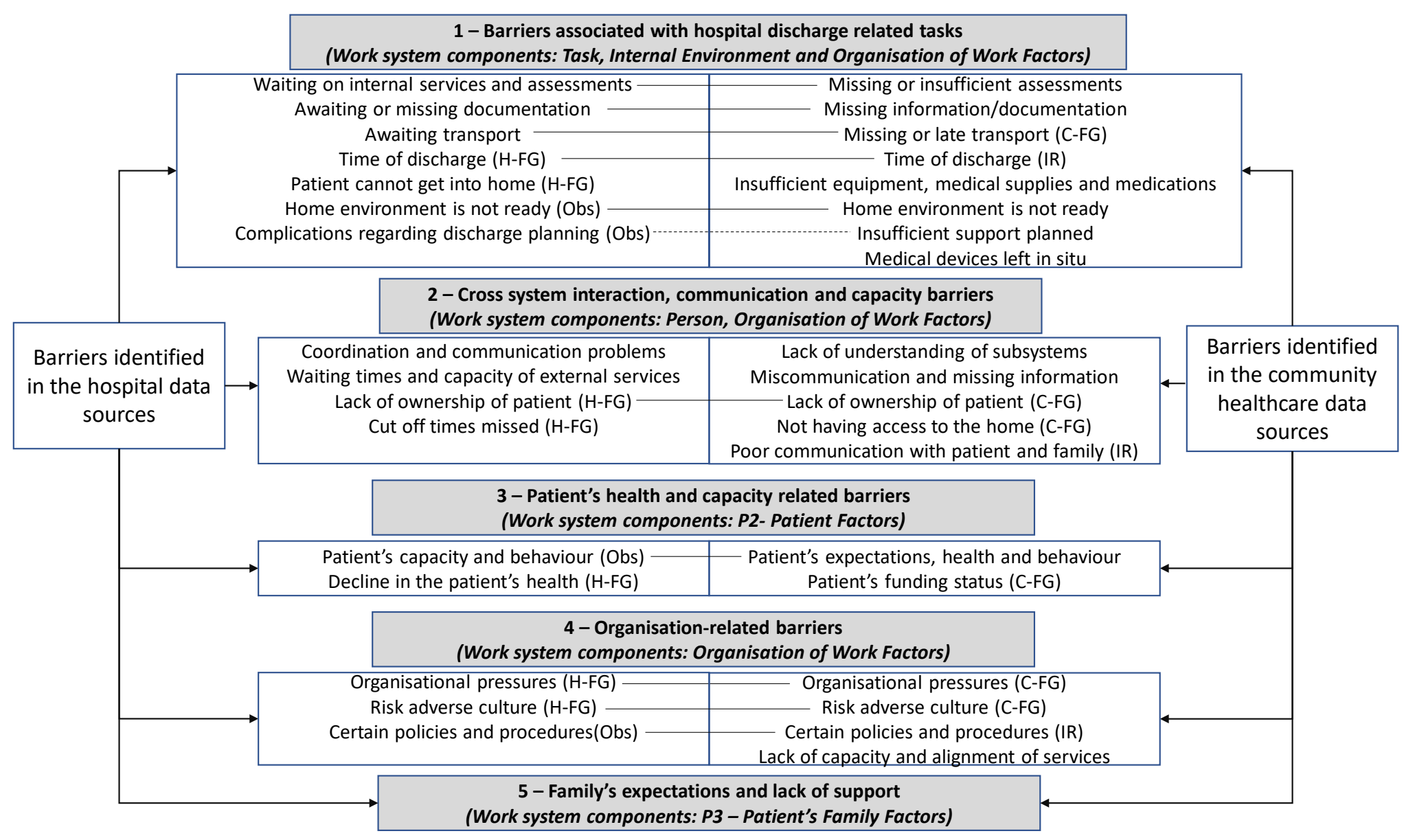

*Obs - Observation data, H-FG - Focus groups with hospital staff, C-FG - Focus groups with community staff, IR - Incident report data

Figure 3: The main themes and subthemes relating to barriers identified in the focus groups, observation and analysis of the incident reports from a hospital and community healthcare perspective and the work system components they relate to. 
Table 1: The main themes and subthemes relating to facilitators for the focus groups held with hospital and community healthcare staff and the associated work system components.

\begin{tabular}{|c|c|c|}
\hline \multirow[t]{2}{*}{ Main Themes } & \multicolumn{2}{|r|}{ Subthemes } \\
\hline & $\begin{array}{l}\text { Focus Groups with Hospital } \\
\text { staff }\end{array}$ & $\begin{array}{l}\text { Focus Groups with Community Healthcare } \\
\text { staff }\end{array}$ \\
\hline \multirow{3}{*}{$\begin{array}{l}1 \text { - Information } \\
\text { availability, } \\
\text { accuracy and } \\
\text { gathering }\end{array}$} & \multicolumn{2}{|c|}{$\begin{array}{l}\text { Key information sources - online systems, family and patient as an information } \\
\text { source, key documents }(W S-P 2, P 3, T 1, T 2)\end{array}$} \\
\hline & $\begin{array}{l}\text { Accurate information and } \\
\text { documentation }(W S-T 1, T 2)\end{array}$ & $\begin{array}{l}\text { Independently gathering information } \\
(W S-T a 4)\end{array}$ \\
\hline & & Transmission of specific information \\
\hline \multirow{3}{*}{$\begin{array}{l}2 \text { - Cross } \\
\text { system } \\
\text { coordination, } \\
\text { communication } \\
\text { and interaction }\end{array}$} & \multicolumn{2}{|c|}{$\begin{array}{l}\text { Good family and patient communication and involvement, including education. } \\
(W S-P 2, P 3)\end{array}$} \\
\hline & \multicolumn{2}{|c|}{$\begin{array}{l}\text { Good coordination of subsystems involved in the process: ( } W S-O 1, O 3, O 7) \\
\text { - Hospital: e.g. pharmacy, discharge lounge and transport department } \\
\text { - Community: e.g. GP, tissue viability nurse }\end{array}$} \\
\hline & \multicolumn{2}{|c|}{$\begin{array}{l}\text { Good coordination and communication with external subsystems involved in the } \\
\text { process (WS1 - O3) } \\
\text { - Hospital: e.g. Referral centre, care homes } \\
\text { - Community: e.g. hospital staff }\end{array}$} \\
\hline \multirow{5}{*}{$\begin{array}{l}3 \text { - Successful } \\
\text { and timely } \\
\text { completion of } \\
\text { pre-discharge } \\
\text { tasks }\end{array}$} & \multicolumn{2}{|c|}{ Patient is medically fit for discharge. $(W S-T a 1)$} \\
\hline & \multicolumn{2}{|c|}{$\begin{array}{l}\text { Patient's home environment is ready for them, including the installation of the } \\
\text { necessary equipment. (WS - IE1) } \\
\text { - For community staff this included also having access to the home. }\end{array}$} \\
\hline & \multicolumn{2}{|c|}{$\begin{array}{l}\text { The correct level of support (e.g. care packages) has been organised in a timely } \\
\text { manner. ( } W S-\operatorname{Ta} 1, \operatorname{Ta} 2, \mathrm{Ta} 6) \\
\text { - For community staff this also included the sending of appropriate and accurate } \\
\text { referrals for the different service providers }\end{array}$} \\
\hline & \multicolumn{2}{|c|}{ Transport home has been arranged for a suitable time of day. (WS - Ta3) } \\
\hline & & $\begin{array}{l}\text { Patient-related health tasks including accurate } \\
\text { assessments, sufficient dressings, medical } \\
\text { supplies and the correct medication have been } \\
\text { sent with the patient }(W S-T a 2)\end{array}$ \\
\hline \multirow[t]{6}{*}{$\begin{array}{l}4- \\
\text { Organisation } \\
\text { of work at a } \\
\text { subsystem } \\
\text { level }\end{array}$} & \multicolumn{2}{|c|}{$\begin{array}{l}\text { Individual behaviours such as being flexible, organised, and being able to } \\
\text { prioritize. }(W S-P 1, P 4) \\
\text { - For hospital staff this also included being able to voice one's opinions } \\
\text { - For community staff this also included previous experience with the patient. }\end{array}$} \\
\hline & \multicolumn{2}{|c|}{$\begin{array}{l}\text { Specific organisational aspects and understanding of the organisational } \\
\text { infrastructure and pressures. (WS-O2,O5,O8,O9) } \\
\text { This included: } \\
\text { - Specific policies and procedures: e.g. Hospital - Escalation procedures, } \\
\text { Community - Procedures of different areas and cut off times } \\
\text { - Specific Roles: e.g. discharge coordinator, community matron } \\
\text { - Understanding the process: For hospital staff this included having a } \\
\text { understanding of discharge procedures. For community staff this includes } \\
\text { knowledge of available resources and contacts. }\end{array}$} \\
\hline & \multicolumn{2}{|c|}{$\begin{array}{l}\text { Time the discharge occurs. For example, discharges before noon are more likely } \\
\text { to go well. (WS - Ta3) }\end{array}$} \\
\hline & \multicolumn{2}{|c|}{$\begin{array}{l}\text { Good teamwork and sharing of information. This includes working as an } \\
\text { integrated team, multidisciplinary team, sharing information and understanding } \\
\text { the roles of other teams in the process. (WS -O1,O7) }\end{array}$} \\
\hline & & $\begin{array}{l}\text { Creating capacity through work scheduling and } \\
\text { triaging referrals. }\end{array}$ \\
\hline & & \\
\hline
\end{tabular}

WS - This refers to the work system components in Figure 2 that these facilitators relate to. 
Table 2: Examples of how barriers and facilitators and local strategies may be connected for the discharge process across the hospital and community healthcare setting.

\begin{tabular}{|l|l|}
\hline \multicolumn{1}{|c|}{ Barrier } & \multicolumn{1}{c|}{ Facilitator } \\
\hline Hospital discharge related tasks not completed & $\begin{array}{l}\text { Successful and timely completion of pre- } \\
\text { discharge tasks }\end{array}$ \\
\hline $\begin{array}{l}\text { Barriers associated with cross system interaction, } \\
\text { communication and capacity }\end{array}$ & $\begin{array}{l}\text { Good cross system coordination, } \\
\text { communication and interaction }\end{array}$ \\
\hline Family's expectations and lack of support & Good family communication and involvement \\
\hline - Missing and inaccurate information & $\begin{array}{l}\text { Independent information gathering } \\
\text { (Community) }\end{array}$ \\
- A lack of trust between systems (Community) & - Missing equipment (Community) \\
- Insufficient support planned (Community) & $\begin{array}{l}\text { Use of alternative resources to provide missing } \\
\text { equipment and unplanned care (Community) }\end{array}$ \\
\hline Capacity of external services (Hospital) & $\begin{array}{l}\text { Create capacity through triage and work } \\
\text { scheduling (Community) }\end{array}$ \\
\hline Cut off times (Hospital) & Cut off times (Community) \\
\hline
\end{tabular}

* The subsystem that identified this theme is printed in brackets. 
Appendix A:

The open questions used to loosely guide the first component of the focus groups, which focused on the things that go wrong and possible error recovery strategies, included:

1. What could go wrong with this task?

2. What external factors influence this task?

3. How do you know the task is going wrong?

4. When you know it is going wrong how do you correct yourself?

5. Do you use this knowledge next time you do this task?

The open questions used to loosely guide the second component of the focus groups, which focused on aspects that work well, included:

1. What is the best way to perform your work? What elements ensure a good discharge? What needs to be in place?

2. What can happen unexpectedly and how do you prepare for it?

3. Are tools in place that assist with this?

4. What do you require for the discharge to be a success from your team/unit?

5. What organisational elements assist in ensuring the discharge is a success? 